\title{
Non-Western Concepts of Language: Are They of Any Use for the Scientific Study of Language?
}

Enrique Bernárdez ${ }^{1}$

\begin{abstract}
Few essential concepts have been so much debated as 'language'; its definition opens the way to the development of new linguistic schools, approaches, etcetera. In this discussion, the Western views on language are taken for granted, as the only point of departure which guarantees and renders possible a scientifically sound science of language. The non-Western conceptualisations of language are very seldom mentioned in mainstream linguistic discussions and when they are, it is mainly as examples of non-scientific, naïve thinking - with a few well-known exceptions.

This paper is organised in three parts: (1) Why -and how- the 'non-Western' conceptualisations of language are set aside as non-scientific, whereas the Western views and conceptualisations are seen as the central factor in linguistic theorising. (2) Examples of important ways of conceptualising language in three ancient literate cultures, viz. India, China, and Japan. (3) Conclusions on the main features of the 'Eastern' approaches which coincide with or may be profitable for present-day linguistics at large.
\end{abstract}

Keywords: linguistic metatheory, History of Linguistics, 'Western' vs. 'non-Western' linguistics, India, China, Japan.

Contents. 1. Introduction: the 'Western' View on Language. 2. Ancient Views of Language in the East. 2.1. India. 2.1.1. Pāninini. 2.1.2. The Western-centred View of Ancient Indian 'Linguistics'. 2.1.3. Abyssal Thinking. 2.1.4. Abyssal Thinking in Linguistics: an Example. 2. 1. 5. Bhartrhhari. 2.2. Linguistics in Ancient China. 2.2.1. Some Common Ideas on Language in Ancient China. 2.2.2. Xunzi's Thinking on Language. 2.3. Linguistic Thinking in Japan: from the Wa to Tokieda Moteki. 2.3.1. Japanese Traditional Thinking on Language. 2.3.2. Takieda Moteki's Tradition-based Thinking on Language. 3. Conclusion.

How to cite this article: Bernárdez, E. (2017) Non-Western Concepts of Language: Are They of Any Use for the Scientific Study of Language?, in Complutense Journal of English Studies 25, 9-25.

\section{Introduction: the 'Western' View on Language}

Linguistics is (assumed to be) the only discipline devoted exclusively to language in all its aspects. This assertion, however, is not as clear and straightforward as it may seem, because e.g., (a) not all aspects of language are the object of interest for all schools of linguistics and (b) it is sometimes far from clear, from the "cognitive

1 Dpto. Filología Románica, Filología Eslava y Lingüística General, Universidad Complutense de Madrid (Spain)

E-mail: ebernard@filol.ucm.es 
turn' in linguistics onwards, whether the main point of interest is language or cognition, or whether language just fulfils the role of a key to the understanding of the human mind. I shall not enter into this discussion here as my main focus will be 'linguistics proper' - together with a number of philosophical approaches to language, as not every culture is as keen as ours on separating disciplines as incompatible ways of working on the same topic.

What is language? We could expect a more or less unitary view in linguistics, but this is not the case, as the views on language diverge greatly. As Dascal and Neto (1991: 46) point out, "cada teoria delimita para si um objeto observacional, ou seja, uma 'porção' da realidade que constituirá o seu objeto de estudos".

But even so there seem to exist some central elements in the most commonly used definitions of language. For instance, that it somehow "exists" independently of its users. This is an extremely old idea that pervades European ('Western') studies on language. The same applies to the following ideas (no exhaustiveness is intended):

(1) An abstract view of language can and must be taken as the centre of study, against the - apparently limitless - diversity of the 'real languages'.

(2) Being abstract, language can be studied independently from the people who use it. In this way, language is separated from culture, history, etc. The abstract language is seen as a symbolic system, built by means of a number of concatenation rules or principles. Language is basically equated with 'language structures'.

(4) Language is non-iconic, i.e., arbitrary: no direct relation exists between the outside world and its linguistic representation(s), e.g. between objects and words, processes and sentences, etc.

Not all schools accept these features at their face value. The speakers are present and active in many approaches to language: text linguistics, discourse studies, pragmatics, limitedly in Cognitive Linguistics. Anthropological linguistics, ethnography of speaking etc. also see language in its relation with its users. The arbitrariness of language has been cast in doubt in recent years. Point (3) seems central to all or nearly all models of language, even if in some approaches structures are now seen as emerging from interaction. But the central point in linguistic analysis continues to be its view of language structures (i.e., de Saussure's système) as central for language description, typological and historical analysis, etc. Beyond all differences there is something common to all these discussions: the concept of language, its objectives and forms of study are derived from a single tradition, which can be termed Western for lack of a better term.

The main purpose of this paper is to review a few non-Western approaches to language. I shall refer mainly to two ancient traditions, viz. India and China, together with some Japanese contributions, both old and new. Of course, the intention is not to provide a history of non-Western thinking about language: I shall

"Each theory delimits its own observational object, that is, the 'portion' of reality that will constitute its object of study" (my translation here and in other quotations unless a different translator is mentioned). 
refer only and exclusively to a few points and the restrictions of length do not allow an exhaustive discussion of their context and historical development.

\section{Ancient Views of Language in the East}

\subsection{India}

Ancient Indian thinking on language was complex and it incorporated different views; I will refer only to two of its most important representatives: Pāṇini and Bhartrihari. The first grammarian's role and significance in modern Western linguistics is well-known, in contrast to the usual neglect of Bhartrihari. This section will offer a possible ideological (more than 'linguistic' proper) explanation for this fact and, in general, for the disregard of non-Western forms of linguistic study, focusing on the notion of abyssal thinking.

\subsubsection{Pāṇini}

In linguistic handbooks, only one non-Western grammarian is included as part of the Western theoretical canon: the Indian Pānini (420-368 BCE), author of an influential grammatical analysis of Sanskrit morphology, the Asțādhyāȳ (Eight chapters). It included 3959 rules for the construction of Sanskrit words, which is seen as antedating the compositional view of language structures as integrated by smaller units. Pāninini's grammar was of special interest for early structuralist linguists, as it reflects one of their main aims in the early 1920s: a formalized description of the language 'in its own terms'. That is, what interested linguists was a well-developed approach to language structures without any reference to speakers, contexts, communicative situations, even without semantics, as in US structuralism and (early) Generative Grammar. It seemed to be an immanent form of linguistics as the one defended by most Western schools within the structuralist paradigm.

Some less well-known ideas of Panini's. In fact, Panini's grammar coexisted (and antedated, and followed) other quite different approaches to language, which did not receive much attention in the West. It was not taken into account, for instance, that Pānini wanted to serve the needs of learners of a language they did not speak in everyday life, viz. Sanskrit and that a descriptive, purely structural description was needed for that purpose. According to one of his most famous followers, Patañjali ( $2^{\text {nd }}$ c. BCE),

the study of grammar (vyākaranam) was meant to maintain the truth of the Vedas, to guide the use of Vedic speech in ritual contexts, and to aid in the clear interpretations of individual human speech. Both Pânini and Patanjali, two major Sanskrit grammarians, were the first to provide a systematic and formal analysis of the grammatical bases of all intended meanings. (Theodorou n.d.) 


\subsubsection{The Western-centred View of Ancient Indian 'Linguistics'}

The acknowledgement of Indian formal grammar as an important 'forebear' of modern linguistics went together with the disregard of other important features and proposals by Pāninini himself and his followers, as Manjali (1997) argues:

It is characteristic of contemporary formal paradigms in Linguistics to choose to ignore all that pertains to cognition and meaning in the grammatical theories that comprise the Indian linguistic tradition. There is near-total neglect of the essential semantic ingredient of the Sanskrit grammar since Panini. ${ }^{3}$ If at all the semantics in this tradition is paid any attention to it is only in a manner completely divorced from the central grammatical principles and categories. Thus, though Chomsky (1965) claimed the Paninian grammar to his 'generative enterprise' because of the recursive properties manifested by the latter, he paid no attention not only to the metaphysical and epistemological ideas that underlie the Indian grammatical systems, but also to an entire literature which would fall within the gamut of philosophy of grammar, especially those authored by Patanjali and Bhartrhari.

Semantic case and the karakas. Western Linguistics, therefore, took only what fitted in their own views and overlooked all the rest. Manjali analyses the karakas, which are interpretable as semantic relations (agent, locative, etc.): "The karakas are recognized by most scholars as basic semantic notions that pivot sentence constructions. They are similar to the case roles/relations proposed in the case grammars". But semantics did not interest the Western formal models at first, so the karakas were simply disregarded. As were also the central, say philosophical notions which established a correlation between linguistic elements and elements of the world: "The karaka notions are conceived as properties of the world corresponding to, though independent of their grammatical/morphological manifestations. Panini himself was probably merely projecting the karakas (literally, 'a factor of action') from morphological occurrences in the form of cases to a set of possible actions in the world".

\subsubsection{Abyssal Thinking}

We may ask ourselves why is it that Western studies of language are so impervious to 'alien' forms of thinking. The Portuguese philosopher, Boaventura de Sousa Santos, proposed the notion of Abyssal Thinking to explain how, in the framework of colonialism, the Western views of science reject any contact with other cultures, denying them any saying in scientific issues: what they do is simply not recognized as science.

Modern Western thinking is abyssal thinking. It consists of a number of visible and invisible distinctions, the invisible ones serving as the foundation for the vis-

\footnotetext{
3 I keep the spellings used by my sources, here as elsewhere.
} 
ible. The invisible distinctions are fixed by some radical lines that divide social reality in two different universes: the universe "this side of the line" and the universe "the other side of the line". The division is such that "the other side of the line" disappears as a reality, becomes inexistent, and is even construed as inexistent. (...). The main characteristic of abyssal thinking is the impossibility of co-presence on both sides of the line. This side of the line will only prevail if it exhausts the field of relevant reality. (Santos 2009: 23-24) ${ }^{4}$

The "visible and invisible distinctions" are those features of our concept of language which are taken as untouchable and unrestrictedly true: the 'dogmas' of linguistics mentioned above, and their derivations, that together form the hard core of contemporary Western linguistics.

According to Santos, abyssal thinking is a consequence of the Western colonial view of the world: "the 'abyssal' cartographical lines that used to demarcate the Old and the New World during colonial times are still alive in the structure of modern Occidental thought and remain constitutive of the political and cultural relations held by the contemporary world system" (Santos 2007: 71: from the English abstract of the paper).

The proposed solution is an Ecologia de saberes, "an ecology of knowledges" (2007: 85), based on the acknowledgment of the plurality of knowledges and interaction among them.

\subsubsection{Abyssal Thinking in Linguistics: an Example}

As an example of abyssal thinking we can take a book which is also an example of good linguistic scholarship: Itkonen's Universal History of Linguistics (1991), that includes detailed descriptions of Linguistics in India, China and the Arab World. Unfortunately, the author evaluates all thinkers (only ancient ones are considered) in terms of their proximity to 'Western-like' forms of linguistics, i.e., inasmuch as they study the system (i.e., the structures) of language (phonology, morphology and syntax) in a formal way and independently of its speakers: if a type of description is easily translated into a Western one, then it is deemed acceptable. Itkonen's defence of the absolute primacy of abstract study is clearly visible in his analysis of the Arab grammarian Sībawayhi's work $\left(8^{\text {th }} \mathrm{c} . \mathrm{CE}\right)$ :

What I find less valuable are Sībawaihi's programmatic statements to the effect that syntactic description should be directly based on actual speech data. ... What is at issue, is the notion that grammatical description should be based on concrete utterances (roughly: Saussure's parole), without any additional level of abstract sentences, or of linguistic norms (roughly: Saussure's langue). This way of thinking has acquired new momentum with the rise of 'suprasentential linguistics' (= discourse analysis, conversation analysis, etc.) in the 70's. (p. 151)

4 For the sake of brevity, in long quotations I do not include the original Portuguese (in other quotations, the original French) version but only an English translation. The original is easily accessible in the sources quoted. 
This way of thinking, where scientific study is limited to its current understanding in the West, underlies his rejection of Chinese linguistics or of Indian writers like Bhartṛhari (he admires Pānini over all the rest). Bhartṛhari and the Chinese philosopher, Xúnž̌, seem devoid of any interest, as their proposals do not seem to fit in the Western model.

Itkonen sees the beginnings in India, China and Arabia as extremely significant - even as better than their European counterparts - but regrets that those distinguished beginnings were not followed by scientific progress - as he claims was the case in the West. Of course, scientific progress is seen in the limited, abyssal form we have made reference to. Itkonen does not mention one single modern or contemporary linguist in those cultural areas. India ends with Bhartrhari, China with a brief mention of Chu Hsih (朱喜, Zhū Xī, 1130-1200 CE), Arabia with al-Fārābī (872-950 CE), while his review of European linguistics begins with Plato and ends in the $20^{\text {th }} \mathrm{c}$. CE.

\subsubsection{Bhartṛhari}

The grammarian and philosopher Bhartrhari belongs to the tradition of Indian grammatical studies initiated by Pānini and continued by Patañjali. Studies on Bhartrhari's linguistic ideas abound, but they are usually published in India and only rarely reach mainstream linguistics: they do not cross over the epistemological abyss. Let me single out an idea of great richness that brings his ideas to the vicinity of contemporary $\mathrm{CL}$ :

Bhartrhari rejects the existence of meanings of individual words. Individual word-meaning is an illusion, according to him. Only the undifferentiated sentence-meaning is real. The sentence-meaning is not a concatenation of wordmeanings as argued by the Mimamsaka philosophers, but to be understood in terms of a complex cognition. Bhartrhari compares this complex cognition with that of the cognition of a picture (citrajnana). "A cognition which embraces many objects at the same time is a complex cognition. As a cognition, it is one but because of the many objects which figure in it, one sees plurality in it, though it is indivisible" (Subramania Iyer 1969: 186, 187). (in Manjali 1997)

Sentence-meaning as primary. According to his top-down approach, Bhartrhari considers sentence-meaning to be primary: The sentence belongs to real language, as used in communication, while the words are there for the sake of the analyst's, i.e., they only serve the needs of linguistic study itself. The relationship between sentence-meaning and word-meaning is compared to that between a holistic picture and its component-parts (Manjali 1997): "Just as an \{sic\} unified perception of composite (picture) can be analyzed (into the preoccupation of component parts) depending upon which part is required to be perceived so likewise is the understanding of the meaning of the sentence".

There is no need to emphasise the modernity of such an approach to meaning. Moreover, in contrast with other scholars who viewed the meaning of words as built from smaller elements, i.e., in a compositional way (Sreekumar 1998: 62ff), for Bhartrhari, words have no real meaning by themselves, and are meaningful 
only when included within a sentence, which Manjali (1996) interprets in gestaltic terms (as in contemporary Cognitive Linguistics).

Sentences and words are compared to a painting where different episodes of a hero's life are depicted. The only way to know and recognise the individual persons, places and actions (i.e., words, phrases...) is to understand the whole story first and then look back at its individual components, the words and the individual scenes. Interestingly, this means that the unit is not strictly the sentence but rather the text, as the kernel of 'real' communication: "The long or short of size of the sentence-token is not a proper criterion for the definition of the sentence. Bhartrhari defines 'sentence' from the point of view of accomplishment of cognition of complete indivisible-meaning" (Tiwari 1997: 198). Thus, a sentence is sphota (see below for further details), as it is the simultaneous manifestation of meaning and a form (sound).

This metaphor or analogy also shows in which sense the posited relation between linguistic expression and reality is to be understood: the sentence is just the linguistic way of expressing 'a cognitive content' related to some process, action, etc., external to language and the mind. It may be useful to remember that Benedetto Croce's theory of expression was rather similar to that view: "La communicazione concerne il fissamento dell'intuizione-espressione in un ogetto che diremo material o fisico per metafora...". (Communication concerns the fixing of intuition-expression in a material or physical object through metaphor) (Croce 19121928: 213).

For Bhartṛhari, as we are seeing, "the meaning of the sentence, the speech-unit, is one entire cognitive content (samvit). The sentence is indivisible (akhanda) and owes its cognitive value to the meaning-whole" (Theodorou n.d.). But also:

The sentence employs analyzable units to express its meaning, but that meaning emerges out of the particular concatenation of those units, not because those units are meaningful in themselves. We analyze language by splitting it up into words, prefixes, suffixes, etc.... but this is indicative of the fact that we 'misunderstand' the fundamental oneness of the speech-unit. Words are only abstracted meaning possibilities in this sense, whereas the uttered sentence is the realization of a meaning-whole irreducible to those parts in themselves.

Reference to reality or reference to cognitive images. A very important point for our purposes here is the idea - typical of the Buddhist philosophers of languagethat words do not refer directly to objects, processes, etc. of reality proper, but to conceptual images of reality (to a metaphorical reality, according to Bronkhorst 2001: 480), and at the same time, the meaning of a word is, according to the theory of the apoha, the negation of everything that is not the object in question: the meaning of 'cow' is therefore not what we understand as cow, but everything that is not a cow (Sreekumar 1998: 66-67) because, in fact, "each time we say the word 'cow' we refer to a different cow, and each cow is actually a different wholly individual entity" (Theodorou n.d.).

Bhartrhari, therefore - to use contemporary terms - sees meaning in cognitive terms, as language expression is tightly linked to cognition and adopts a top-down approach, seeing words as non-meaningful by themselves in isolation and defines their meaning as the 'complementary set' of the objects the word in question is the 
expression of, thus fulfilling the function of separating things from each other (Bronkhorst 2001: 481)

Theory of sphota. Everything seems to be covered by the theory of sphota: "Meaning is the particular instantiation of the activation, through an explosion or 'bursting forth' (sphota) ${ }^{5}$ in the intellect (pratibha) of the hearer. What is important in these views is the dynamic perspective attached to both meaning and form". And:

It is difficult to say that whether Bhartrhari's notion of sphota coincided with the word in the intellect, or with the spontaneous 'bursting forth' of recognition of meaning. Probably, both have a role in meaning grasping. If this hypothesis is correct then we can think of the word-in-the-intellect aspect of sphota as a kind of mental (transcendental) schema, though as Kant would say, "hidden deep within our soul" and the flash-like understanding akin to the "spontaneous synthesis" supposed by Kant. (Mishra 1985/1986)

The sphoța theory was developed by Bhartrihari and includes many significant intuitions. We have already discussed the view of the sentence as the centre of expression. Nair (2014: 13) sees this idea in the general framework of the sphota:

According to Bhartrhari the speech and thought are only two aspects of the same speech principle. A sentence is to be considered as a single undivided utterance and its meaning as an instantaneous flash of insight (pratibhā). The sentence is the fundamental linguistic fact and words are only its unreal abstractions. The sentence meaning is to be grasped as a unity. The division into words and wordmeanings are only useful in the study of language but does not exist in reality.

Bhartrhari and Linguistic Relativity. Finally, mention can be made of Bhartrhari and Buddhist thinking in connection with the primacy of language and its influence on thinking; i.e., the Linguistic Relativity Hypothesis. Theodorou (n.d.) dwells on this topic in some detail:

[A]ccording to [Bhartrhari], cognition is entirely language-dependent in that the structure of our cognitive states is determined by grammar. But Bhartrihari's theory posits knowledge as a matter of specifically linguistic construction. (...) the structure of language shapes how we categorize the objects of our experience and our descriptions of reality as a whole. Even at the most immediate levels of awareness, we must conceptualize and therefore interpret the contents of sense perception. Thus, at the level of pure sensation, the sensory core is already saturated, as it were, with the "deep structure" of language.

Conclusion. As can be seen, Bhartrhari's stance antedates similar discussions on the issue of whether perception operates directly on the objects of reality, or whether culture and language also play a role. Suffice it to say as a final conclusion

Sreekumar 1998 compares this term and notion with the Greek logos / $\lambda$ ó $o \varsigma$. Its "dictionary meaning" is "bursting": "the idea bursts or flashes on the mind when the sound is uttered". (Sreekumar, p. 93) 
that Bhartrhari's theory of language and grammar is rather close to some presentday ideas in Cognitive Linguistics and other recent approaches to language in the West (Davidoff et al. 2008; Nisbet \& Miyamoto 2005), as the gestaltic, embodied view of meaning.

\subsection{Linguistics in Ancient China}

\subsubsection{Some Common Ideas on Language in Ancient China}

The Chinese began thinking about language even before the arrival of Buddhist thinking from the Indian subcontinent. It then continued under its influence within a field that can be termed linguistic as well as purely philosophical; in this first section a number of important ideas in Chinese linguistic thinking will be very briefly discussed. First of all, the issue of the written language and its complex relation to the spoken language, one of the topics that had never been the object of in-depth study among Indian scholars and that is basically overlooked in contemporary linguistic discussions in Europe, as the written language is seen as a secondary phenomenon, of no special significance for the study of language 'proper'. The reason may probably lie in the type of script itself. Whereas the Indian devanāgar $\bar{l}$ script was essentially a direct representation of the sounds, the Chinese system is of a completely different nature. The phonetic value of the characters was - and is - practically inexistent, although some attempts were made to use them as 'purely phonetic' markers without any reference to meaning; such attempts were ultimately rejected by the literate community and disappeared, in such a way that the Chinese writing system is - and has been for centuries- essentially semantic and only very limitedly phonetic.

Writing and speech; the role of the 'word' or 'name'. In Chinese, then, according to an ancient myth, writing and speech were two different things and created in different ways (Geaney 2010). This fact notwithstanding, in Early Chinese the character, syllable or 'word' (ming 名) seemed to mean something like 'visible (i.e. writing) + audible (sound)'; according to Geaney (2010: 253) "a linguistic unit that is readily identifiable both across writing and speech". In fact, no really abstract view of language had existed from the earliest literary times, and for Western scholars this absence was seen as a serious flaw, because they could not understand that the Chinese discussed 言 yán, 'speech', a concrete audible phenomenon, instead of the abstract 'language' (Geaney 2010: 250). At the same time, yán refers to an action, as speech is not viewed as a state but as a process, in contrast to most Western conceptions of language.

Let us also mention the debates on the relation between language and reality, looking for the relation between 'names' ming and 'things/reality' shi (名- 事) or the doctrine of the Confucian theory of the Rectification of Names which endeavoured to guarantee that the 'right' names were applied to the 'right' objects (e.g., political positions and the like) and proposed to change those names which did not fulfil the condition. The Confucian theory relies on the social and personal abilities that are expected to correspond to a name: if you are a leader but your behaviour is not the behaviour expected in a prototypical leader (as defined in accordance with Confucius' philosophical thinking), then you are no leader and the term cannot be 
applied to you. The same applies to being a father, a friend, an artisan, or whatever. The linguistic aspect of the topic is secondary, what matters is the adequacy of someone's behaviour.

Chinese linguistic thinking centred around the concept of word, or name, ming (名), and not the (inexistent) morphology or the sentence in Classical Chinese, as, e.g. word order was seen to mirror the natural processes described (Bao 1990), in contrast to the well-developed approaches to morphology and even syntax in India. This may be seen as a consequence of (A) the script itself, where every character corresponded to a syllable and most frequently a word, and (B) the grammatical structure of the language:

... characters did not take part-of-speech modification. Chinese writers did not notice the functional parts that point to sentential composition. Further, in their topic-comment structure, subjects were optional and comparatively rare in written texts. The familiar Western idea of a sentence 'frame' that speakers 'fill in' with functional units would not be as inviting for Chinese linguistic thinkers. (Philosophy of Language in Classical China).

Many more aspects of language philosophy have to be set aside here. For instance, the equation name $=$ ritual (action). An exceptionally important point is the view of the social conventionalisation of characters and words and consequently of language as a whole, which may explain Confucius and his followers' interest in the changing of names, i.e., the conventions. Language, therefore, is essentially convention.

\subsubsection{Xunzi's Thinking on Language}

The philosopher 荀子 Xún Ž̃ (312-230 BC) can be seen as the most original and interesting thinker on language in Ancient China. His thinking is of extreme interest and importance for contemporary linguistics, but it is so rich and complex that only a small selection of interesting points can be presented here.

First of all, he follows the Chinese Confucian tradition of the primacy of practice or activity, the view of language as part of the (ritual, ethic) activity, etc.:

Early Chinese philosophers conceived of language primarily in practical terms. They took its main function to be guiding behavior and not, say, stating facts. Language guides behavior not only when used explicitly to issue commands or suggestions, but also by embodying value-laden distinctions, such as the distinction between right and wrong. (...) For Xunzi, the guidance provided by language is essential for social order, and this provides the motivation for his interest in language. Early Chinese philosophers' practical conception of language is especially obvious in the Confucian doctrine of the rectification of names. This doctrine focused on role-terms, such as "jun" ("ruler") and "fu" ("father"), and held that bearing one of these 'names' commits a person to certain norms; conversely, if a person does not live according to the norms associated with a roleterm, then he or she is not appropriately named by that term. One passage in the Confucian Analects implies that it is an important purpose of government to en- 
sure that people act in accordance with the terms used to name their roles. (Robins 2014)

His view on the language-reality relation may be defined, to use present-day terms, as cognitive and embodied: "For Xun $\mathrm{Zi}$, the name-referent (ming-shi) relation is not one between language and the world. Rather, it is a relation between language and the world as perceived by the mind" (Bao 1990). That is, reality is perceived by the senses and re-elaborated by the mind. Remember what was said above on Bhartrhari's similar ideas.

Xunzi analyses nouns as abstract references to all the individuals that may be termed with a particular noun. That is, reference is not individual but global. A ming like niú (cow) does not refer to individual cows but to 'cow-ness'. This reminds us of some recent views on 'unitizing' and 'unitizer languages':

[...] languages with sortal numeral classifiers construe all nouns as unbounded (uncountable), and the classifier -partitive, measure, group, arrangement, or sortal-UNITIZES the kind denoted by the noun so that it can be counted. (Croft 2001: 119)

Chinese could be defined as a unitizer language, as the identification of any individual object calls for the use of a classifier - including the "universal classifier" ge (个) which changes a general concept into a concrete instance. Did Xunzi 'discover' unitizing in the $3^{\text {rd }} \mathrm{c}$. BCE? In this respect, see Mou (1999).

Xunzi's central ideas in our context. Let me summarise the points in ancient Chinese and Xunzi's linguistic thinking that seem most interesting:

(a) Separation of writing and speech as two different phenomena-joined together, however, by a view which sees pairs as essential for harmony; in this case, sound and figure.

(b) Language is more than anything yán, that is, speech, i.e., sound or, more exactly, the action of producing sounds with communicative intent.

(c) The core of language is the names (ming), as sentences are seen as isomorphic, or iconic, with the processes of reality they express.

(d) A direct relation exists between language, i.e. names (ming) and reality, i.e., the objects the word represent (shi). This leads to a number of logical problems which Xùnzî tried to solve by positing an indirect relation: from the real objects through the senses to the mind; it is the objects in the mind that names are given to. This cognitive view of meaning is an obvious parallel to Bhartrihari's ideas.

(e) Names have values; objects must correspond in their values to those assigned by the names - this being the core of the theory of rectification of names.

(f) Names do not signify concrete individual objects, but general objectual categories, as in contemporary unitizing theory. 


\subsection{Linguistic Thinking in Japan: from the Wa to Tokieda Moteki}

\subsubsection{Japanese Traditional Thinking on Language}

The Japanese tradition is basically a continuation of Chinese and ultimately Indian ideas. Even previously to Chinese contact, among the Wa people of Japan, however, the idea of the identity of world and language was prevalent — as in early China and elsewhere:

The $W a$ thought that words had some magic force. In the ancient Japanese world, language and the world were one single thing. Language was not reduced to simple signs, to tools without a substance as nowadays, but they had something intimately linked to the world, the human beings and the objects. It was seen as something alive. In this representation, the word was composed of mono and koto. The mono "objects" are constant existences in time whereas the koto "events" were produced in the relations among humans or between man and thing in a temporal fashion. Ancient men thought that the koto were manifested in the form of words (言) or in the form of facts (事). And both koto were undistinguishable. Because for the Japanese of ancient times they are the two faces of a single event. The $W a$ thought that, in this way, the uttered words exerted a force on the world. This force manifested through the word is known as the kotodama. (Tereda Akira 2009: 164$)^{6}$

The Chinese distinction ming/shi appears in Japan in the form of koto vs. mono; in both languages, 言 versus 事. The concept of the kotodama, however, 言霊, as a singular magic or mystical power that dwells in names (remember the Indian sphota, a concept I see as distantly similar), seems to be exclusive of Japanese culture. Language, at the same time, is a form of action (Wlodarczyk 1982: 7), a point where most cultures throughout the world seem to agree but which is much too often absent from Western contemporary linguistics.

The introduction of the Chinese writing in the $5^{\text {th }} \mathrm{c}$. CE leads to thinking about language in a material form; the early development of syllabic, i.e. phonetic scripts like the hiragana led to a very sophisticated phonetic analysis as witnessed by the classification and ordering of the syllables (Wlodarcyk 1982). This opened the way to morphological analysis, with the need to differentiate between 'empty' and 'full' words (monème/morphème, koenemathem vs pleremathem, etc in 20c European linguistics).

\subsubsection{Takieda Moteki's Tradition-based Thinking on Language}

Up to this moment we have only considered ancient approaches to language. In this section I shall review a few features of linguistic thinking by a prominent $20^{\text {th }}$

\footnotetext{
6 Original French not included for the sake of brevity, as in the following quotes.
} 
c. linguist, who considered and developed his main ideas for the Japanese and Chinese traditional notions that we have been considering above.

Tokieda Motoki (時枝 誠記) 1900-1967, developed his basic ideas in his main publication, The Principles of Japanese Linguistics (國語學原論, Kokugogaku genron) published in 1941. He tried to counteract the Western influence which arrived in his country through de Saussure's Cours de linguistique ggénérale:

According to Tokieda, language is not defined as the combination of sounds and meaning, but as the very complex process through which - by the medium of a phonic or graphic channel-expression takes place and comprehension is accomplished (cf. Humboldt for whom language was not just a product but also an activity). For this reason, if Saussure bases his linguistic theory mainly on the study of langue, Tokieda proposes to devote oneself in the first place to parole. It is thus that his theory of the language process (gengo katei-setsu) was born (...). (Wlodarcyk: 13-14)

Tokieda's interest in creating a Japanese linguistics on its own bases and free from Western influences may be a consequence of his nationalistic, even imperialistic view of Japan, according to Culiberg's $(2011,2015)$ interpretation. In any case, his theory looks interesting: Seeing language in terms of activity makes it possible to study it as a form of human expression, at a pair with painting, music, and dancing (Garnier 1982: 72). Being an expressive activity, it is in the hands of the communication partners: "Language is primarily the form adopted by a speaker individual's process of expression; language is the activity itself by which the content of one subject's thinking is expressed, through sound or written symbols".

Language in communication. Language does not exist "out there" as a kind of "independent object"; another consequence is the rejection of a view of language as an abstract phenomenon: " ... the idea Tokieda attacks more insistently is the idea that general linguistics is the favoured system as opposed to the individual languages. The only real theory is the one born from the observation of the object" (Garnier 1982: 74). Moreover, "The object of experience cannot be but the activity itself. Language is not thinkable outside the subject who practises it; language must be understood as a psychic process and not as 'something' that can be said, understood, written, or read" (Garnier 1982: 75). Consequently, we get to a new understanding of 'language':

Tokieda's aim is thus to define the nature of language. For him, the common conceptions in general linguistics are either organicistic, language as a living organism, or sociological, language as an element of some man-produced culture. They leave many phenomena unexplained. The only possible and effective approach is, according to Tokieda, viewing language in everyday experience and in the form in which every human uses it, i.e., as the process by which a speaking subject expresses the content of his psychic activity or understand the content of the psychic activity expressed by another subject. (Garnier 1982: 73) 
We see that Tokieda is anticipating some present-day alternatives to the mainstream view of language outlined at the beginning of this paper-and which were criticised by Itkonen. He also rejects the traditional view of a process of communication where the 'listener' is just a passive decoder:

A speaker says: "inu ga iru" (there is a dog). Even if a listener B can attribute some meaning to this chain of sounds, it does not mean that he is experiencing language in the same way as A, that he gives this chain of sounds the same meaning given by A. For instance, in order to be able to give exactly the same meaning to the word "dog", B must have the same experience of language as A, reproducing in himself the same process that took place in A, in order for A's language to become his own language. This is the interpretation operation. [...] Language is always "done". (Garnier 1982: 76)

Observations like these have been the rule in discourse and text-centred approaches to language and communication: the speaker and the listener are equally active in the process of communication.

In the words of Fuse (2010: 86):

Tokieda's language-as-process theory clearly denies a view of language as a static entity. Tokieda insists that language is a mental process, whereby speakers express their own thoughts or understand the thoughts of others. One can only 'observe' the other person's language acts through an interpretation of that act, because language is essentially subjective; it is impossible to experience the other person's mental process per se as it is. Once language is defined as subjective human action in which people express their thinking, it is possible to consider and identify the preconditions that enable such action.

Tokieda was not alone in his rejection of the mainstream linguistics of his time, i.e. Saussure's and Structuralism in general. But it is no wonder that his work remained practically unknown to most Western scholars: in a way, he represented the opposite of what was - and still is, for a number of linguists - the 'dogmatic core' of Linguistics.

Linguistic life. As a result of his theoretical thinking, Tokieda proposed the concept of gengo seikatsu (言語生活), linguistic life, a concept which may be seen as antedating some very recent approaches to language (and some much older ones, both in Western and non-Western linguistic study):

If we think that language is an act or rather an activity of man directed toward a goal, it shall then be considered as a form of human life and it can be termed 'linguistic life' [...]. And he adds with regard to methods of research: "The idea of grasping language as an activity did not exist until now in linguistic research, as this focused only the structural aspect of language. In such researches, emphasis has been laid thus far on the pre-production matter of language and the greatest importance has been attached to the analysis of its structural elements. The linguistic research on language life makes the activity itself the object of re- 
search. Consequently, what will become the main object of study will be the dynamic reality of language, that is, the phenomenon of communication as an activity of production and an activity of understanding" [...]. (Dhorne 1982: 65)

Conclusion: Tokieda's main points. Let me summarise Tokieda's main points, which might be readily integrated in a new view of language and linguistics within the Ecology of Knowledges proposed by Augusto de Sousa Santos:

(a) Language is not an abstract 'object' but a product of human activity: a form of expression of the 'speaker' and an equally active response by an active 'listener'.

(b) It is in the individual languages where language activity can be observed: there is no other way to observe human activity: introspection cannot suffice.

(c) Language is a mental process.

\section{Conclusions}

The (much too brief and necessarily superficial) analysis offered in these pages has served to identify a number of features of linguistic thinking in India, China and Japan, which prefigure some essential tenets of some very recent linguistic models - even if some of those ideas were present a long time ago, albeit never within the mainstream schools. Such are for instance (a) the role of perception in language, (b) the cognitive (earlier called 'mental') character of meaning-as opposed to the vericonditional models of meaning using reference to 'external reality', an idea which is frequent in Structural Linguistics that unfortunately is still present, even in Cognitive Semantics (Brandt 2005); (c) the need to take whole communication products (text, discourse, conversation) as the core of language and correspondingly its study; (d) the essential unity of language and the socio-cultural group using it; (e) the primacy of language in interaction over abstract structures; (f) the active role of the participants holding the key for the understanding of language dynamics. And last but foremost, (g) the character of language as an activity instead of a static, abstract, isolated construct.

The (radical) difference between speech and written language, typical of Chinese linguistic thinking, could be incorporated in 'Western' linguistics, leading to a tripartite distinction: speech-sign language-written language, all of which together form the complex picture of 'language', instead of the highly reduced and simplified views current throughout the $20^{\text {th }}$ century. Taking non-Western thinking in consideration thus leads to the reinforcement of some recent ideas (within an extremely old tradition in some cases) and the possible development of some new insights in the extreme complexity of language. We have to avoid Abyssal Thinking in linguistics and reject the idea that everything outside our own way of thinking is simply useless (as was visible in Itkonen's book as shown above). 


\section{References}

Bao, Zhiming (1990). Language and world view in ancient China. Philosophy East \& West 40.2: 195-219.

Brandt, Per Aage (2005). Mental spaces and cognitive semantics: A critical comment. Journal of Pragmatics 37: 1578-1594.

Bronkhorst, Johannes (2001). The peacocks's egg: Bhartrhari on language and reality. Philosophy East and West 51.4: 474-491.

Croce, Benedetto (1912-1928). Breviario di estetica + Asthetica in nuce. Milano, Adelphi, 1990: 216. (Originals from 1912 and 1928 respectively). Cf also Croce 1902: $165 \mathrm{ff}$.

Croft, William (2001). Radical Construction Grammar: syntactic theory in typological perspective. Oxford: Oxford University Press.

Culiberg, Luka (2011). Towards a Theoretical Approach to the Understanding of Language Ideologies in Post-Meiji Japan. Acta Linguistica Asiatica 1.1: 25-37.

Culiberg, Luka (2015). Japonski jezik med nacijo in imperijem: Tokieda Motoki in aporija nacionalnega jezika. Asian Studies III (XIX).1: 225-240.

Davidoff, Jules, Elisabeth Fonteneau and Julie Goldstein (2008). Cultural Differences in Perception: Observations from a Remote Culture. Journal of Cognition and Culture 8: 189-209.

Dascal, Marcelo and José Borges Neto (1991). De qué trata a lingüística, afinal? Histoire Épistémologie Langage 13.1: 13-50. Doi: 10.3406/hel.1991.2323.

Dhorne, France (1982). "Gengoseikatsu" ou la vie langagière (objectifs et méthodes des recherches). Langages 68: 63-69.

Fuse, Naoki (2010). Tokieda Motoki and His Theory of 'Language As Process'. MA Thesis, The Ohio State University.

Garnier, Catherine (1982). Tokieda contre Saussure, pour une théorie du langage comme processus. Langages 68: 71-84.

Geaney, Jane (2010). Grounding "language" in the senses: what the eyes and ears reveal about ming 名 (names) in early Chinese texts. Philosophy East \& West 60.2: 251-293.

Itkonen, Esa (1991). Universal history of linguistics: India, China, Arabia, Europe. Amsterdam: John Benjamins.

Jules Davidoff, Elisabeth Fonteneau and Julie Goldstein (2008). Cultural Differences in Perception: Observations from a Remote Culture. Journal of Cognition and Culture 8: 189-209.

Manjali, Franson D. (1996). Sentence Meaning as Dynamic Gestalts: Semantic Archetypes and the Kiiraka Theory. Studies in Humanities and Social Sciences 3.1: 71-88.

Manjali, Franson D. (1997). The Karaka Theory of the Indian Grammarians. Semiotics Institute Online. $<\mathrm{http}: / /$ semioticon.com/sio/courses/dynamical-models-in-semioticssemantic/indian-grammatical-theory $>$ (Accessed November 17 2017).

Mishra, K.K. (1985/86). Bhartrhari's theory of sphota. Indologica Taurunensia XIII: 115121. <www.indologica.com/volumes/vol13/vol13_art08_MISHRA.pdf> (Accessed November 17 2017).

Mou, Bo (1999). The structure of the Chinese language and ontological insights: A collective-noun hypothesis. Philosophy East and West 49.1: 45-62.

Nair, Manu V. (2014). The Sphoța Theory of Bharțhari. Seminar Report submitted by Kavitha Raju, Manu. V. Nair for the award of the degree of Master of Technology. Government Engineering College Sreekrishnapuram. Palakkad. 
Philosophy of Language in Classical China. <http://www.philosophy.hku.hk/ch/lang.htm> (Accessed November 17 2017).

Robins, Dan (2014). Xunzi. In Edward N. Zalta, ed.

Santos, Boaventura de Sousa. (2007). Para além do pensamento abissal: das linhas globais a uma ecologia de saberes. Novos Estudos-CEBRAP 79: 7194. <https://dx.doi.org/10.1590/S0101-33002007000300004> (Accessed November 17 2017).

Santos, Boaventura de Sousa (2009). Para além do pensamento abyssal. In Boaventura Santos and Maria Paula Meneses, eds., 23-72.

Santos, Boaventura and Maria Paula Meneses, eds. (2009). Epistemologias do sul. Coimbra: Edições Almedina.

Sreekumar, M. (1998). A comparative study of Sphota theory of language and F.D. Saussures theory of sign. Department of Philosophy, University of Calicut. $<$ http://shodhganga.inflibnet.ac.in/bitstream/10603/31822/10/10_chapter\%204.pdf $>$ (Accessed November 17 2017).

Subramania Iyer, K.A. (1969). Bhartrhari. A Study of Vakyapadiya in the Light of Ancient Commentaries. Poona: Deccan College Postgraduate Research Institute.

Terada, Akira (2009). L'évolution des idées sur la langue dans le Japon ancien. Histoire Épistémologie Langage 31.2: 163-173.

Theodorou, Stephanie (n.d.): Bhartrihari. Internet Encyclopaedia of Philosophy. $<$ http://www.iep.utm.edu/bhartrihari/> (Accessed November 17 2017).

Tiwari, D.N. (1997). Bhartrhari on the indivisibility of single-word expressions and subordinate sentences. Indian Philosophical Quarterly XXIV.2: 197-216.

Wlodarczyk, André (1982). Théories du langage au Japon. Langages 68: 7-16 (La linguistique japonaise). Doi: 10.3406/lgge.1982.1129.

Zalta, Edward N., ed. (2014). The Stanford Encyclopedia of Philosophy (Spring Edition). $<$ http://plato.stanford.edu/archives/spr2014/entries/xunzi/> (Accessed November 17 2017). 